\title{
The Research of Refugee Quota Plan on the Basis of Grey Model and Muti-Objective Analysis
}

\author{
Hui-nan Zhu' ${ }^{1}$, Gang $\mathrm{He}^{1}$, Zi-hui Zhang ${ }^{2}$, Xue-hui Wang ${ }^{2}$, * \\ ${ }^{1}$ Humanities Department, Tianjin Agricultural University, Tianjin, China \\ ${ }^{2}$ College of Basic Sciences, Tianjin Agricultural University, Tianjin, China
}

\section{Email address:}

1004023009@qq.com (Hui-nan Zhu),540762751@qq.com (Gang He), 929222123@qq.com (Zi-hui Zhang), intianjin@163.com (Xue-hui Wang)

${ }^{*}$ Corresponding author

\section{To cite this article:}

Hui-nan Zhu, Gang He, Zi-hui Zhang, Xue-hui Wang. The Research of Refugee Quota Plan on the Basis of Grey Model and Muti-objective Analysis. Applied and Computational Mathematics. Vol. 6, No. 3, 2017, pp. 137-142. doi: 10.11648/j.acm.20170603.12

Received: March 29, 2017; Accepted: April 11, 2017; Published: May 22, 2017

\begin{abstract}
In recent years, it brings lots of challenges for European governments with the influx of refugees. Hence, we build relative models to solve this situation. In this paper, we get relative data from UNHCR statistical yearbook and make a short-term prediction of refugee number via grey GM $(1,1)$ model at first. Then we select five limited indexes for the multi-objective analysis, in order to build the optimal quota model and get optimal quota plan. Finally, we put forward some feasible suggestions to EU about refugee quota plan on the basis of former analyses.
\end{abstract}

Keywords: Refugee Quota Plan, Grey Model, Multi-Objective Analysis

\section{Introduction}

Refugee policies are not only the problem concerned universally by the international community, but also an important cooperation area in the process of the EU integration. The EU [1] and its member states have issued a series of policies to refugee problems and obtained certain achievements. Whereas, the integration of European refugee policies started late and there are still many crises in this process. With the refugee problems become increasingly complex, the refugee export countries, recipient countries and transit countries still need to work together [2]. As we know, any policies are the products of specific era and environment, so it will be a big challenge for existing policies when the historical backgrounds and surroundings have tremendous changes.

Now Europe is facing a great pressure because of refugee problems, and the primary causes of increasing refugees are the regional conflicts and natural disasters [3]. However, the international place and domestic situation of EU all have changed a lot after entering the 21 st century [4]. At the same time, refugee problems emerge new features and the existing refugee policies arise many kinds of issues. It is imperative to formulate and improve refugee policies, hence doing research on EU refugee quota policy is extremely in need.

\section{Research Questions}

It is necessary to have a continuous understanding about the number of refugees pouring into Europe, especially the number of refugees for several consecutive years. And it can build a good data foundation for the following establishment of models.

(a) The major issue to be addressed is the establishment of scientific refugee population prediction model [5], in order to reasonably predict the number of refugees in next few years. We need to learn about the current situations of accepting refugees as well as the difficulties in settling, and quantify these limiting factors.

(b) According to the quantitative limiting factors, we try to build an optimal model of allocation plan for getting the optimal refugee quota plan.

(c) Evaluate and analyze the above plan existing deficiencies.

(d) Put forward our opinions to the refugee quota plan. 


\section{Research Assumptions}

(a). Migration occurs yearly.

(b). There are no unexpected disasters that have impact on the choice of the refugee.

(c). Ignore the data of countries which refugee number is less.

(d). The difference of languages cannot influence the refugee quota plan.

(e). The refugee mortality in the process of migration is consistent.

\section{The Prediction of Refugee Number}

For refugees into Europe mostly from the Middle East and North Africa, we use the number of refugees in Middle East and North Africa as raw data to build Grey Model [6]. There are too many factors can influence the refugee number, such as the war, politics and religions, so we do not predict the number for more years in order to guarantee the accuracy of these figures.

\subsection{The Building of Grey Model}

The number of refugees in the Middle East and North Africa of origin and asylum are found in UNHCR statistical yearbook, as shown in Table. We can get the flow volume of refugees by doing subtraction between the figures in Table 2, as shown in Table 2. We choose this portion of refugees as the number of migration into Europe for most of them migrate into Europe.

Table 1. The refugees in North Africa and the Middle East in recent five years.

\begin{tabular}{lllllll}
\hline Year & $\mathbf{2 0 1 0}$ & $\mathbf{2 0 1 1}$ & $\mathbf{2 0 1 2}$ & $\mathbf{2 0 1 3}$ & $\mathbf{2 0 1 4}$ & $\mathbf{2 0 1 5}$ \\
\hline $\begin{array}{l}\text { Refugee of } \\
\text { origin }\end{array}$ & 1889712 & 1669384 & 1519027 & 2556619 & 2898533 & 2675408 \\
$\begin{array}{l}\text { Refugee of } \\
\text { asylum }\end{array}$ & 1967653 & 1717962 & 1743684 & 3112851 & 4499740 & 5391192 \\
\hline
\end{tabular}

Constructing the $X_{(0)}$ sequence, $k$ stands for seats of each number in sequence.

Table 2. The Corresponding graph of $X_{(0)}^{(1)}$.

\begin{tabular}{lcccccc}
\hline $\mathbf{X}(\mathbf{0})(\mathbf{1})$ & $\mathbf{X ( 0 ) ( 1 )}$ & $\mathbf{X ( 0 ) ( 2 )}$ & $\mathbf{X}(\mathbf{0})(\mathbf{3})$ & $\mathbf{X}(\mathbf{0})(\mathbf{4})$ & $\mathbf{X ( 0 ) ( 5 )}$ & $\mathbf{X ( 0 ) ( 6 )}$ \\
\hline $\begin{array}{l}\text { Refugee } \\
\text { population }\end{array}$ & 77941 & 48578 & 224657 & 556232 & 1601207 & 2715784 \\
\hline
\end{tabular}

Make a sum of $X_{(0)}$ and get the sequence of ${ }^{X_{(1)}}, \mathrm{k}$ stands for seats of each number in sequence. Make a sum of $X_{(1)}$ and get the follow sequence.

$$
X_{(1)}=\left\{x_{(1)}(1), x_{(1)}(2), x_{(1)}(3), x_{(1)}(4) \ldots x_{(1)}(k)\right\}
$$

Mean generation with consecutive neighbors to ${ }^{Z_{(1)}}$, let $X_{(1)}(k)=0.5 x_{(1)}(k)+x_{(k-1)}(k)$, then we have.

$$
Z(1)=\left\{\left(z_{(1)}(2), z_{(1)}(3), z_{(1)}(4) \ldots z_{(1)}(k)\right\}\right.
$$

Thus the data matrix $B$ and the data vector $Y$ are.

$$
B=\left[\begin{array}{cc}
z_{(1)}(2) & 1 \\
z_{(1)}(3) & 1 \\
z_{(1)}(4) & 1 \\
\vdots & \vdots \\
z_{(1)}(k) & 1
\end{array}\right] \quad Y=\left[\begin{array}{c}
x_{(0)}(2) \\
x_{(0)}(3) \\
x_{(0)}(4) \\
\vdots \\
x_{(0)}(k)
\end{array}\right]
$$

Do least square estimation to parameter list $a_{n}=[a, b]^{T}$ then we have

$$
a_{n}=\left(B^{T} B\right)^{-1} B^{T} Y=B^{T} Y
$$

Calculate

$$
B=\left[\begin{array}{l}
a \\
b
\end{array}\right]=\left(B^{T} B\right)^{-1} B^{T} Y
$$

Get the predication models

$$
x_{(1)}(k+1)=\left(x_{(1)}(1)-\frac{a}{b}\right) e^{-a k}+\frac{a}{b}
$$

Then we have the population change of refugees in GM (1, 1)

$$
q(k)-0.188422 z^{(1)}(k)=9.54872
$$

Then we have the GM $(1,1)$ serial number responsive of the population change of refugees in time series

$$
x_{(1)}(k+1)=223830 e^{100000 k}-145890
$$

\subsection{Model Test-Residual Test}

According to the prediction formula, calculate $X_{(1)}(k)$ then we have

$$
\begin{aligned}
X^{(1)}(k)= & \{77941,230295.75,467240.74, \\
& 947971.93,1923314.24,3902159.52\}
\end{aligned}
$$

Make IAGO to get $X^{(0)}(k)$ sequence $k=1,2, \ldots, 6$

$$
\begin{gathered}
X^{(0)}(k)=\{77941,230295.75,467240.74 \\
947971.93,1923314.24,3902159.52\}
\end{gathered}
$$

Original sequence

$$
\begin{aligned}
X_{(0)}(\mathrm{k})= & \{77941,48578,224657, \\
& 556232,1601207,2715784\}
\end{aligned}
$$

Calculate the absolute residua and relative residuals sequences. Absolute residua sequence:

$$
\Delta^{(0)}=\{0,0.02,0,0.04,0.02,0.01\}
$$

Relative residuals sequence:

$$
\varphi=\{0,0.06 \%, 0,1.18 \%, 0.53 \%, 0.26 \%\}
$$

The relative residuals is less than $1.19 \%$, thus the accuracy of this model is high. 


\subsection{Model Test—Conduct the Relational Degree Test}

Calculate the absolute residua sequence between ${ }^{x_{(0)}}$ and $x^{(0)}$, then we have $\Delta^{(k)}$

$$
\begin{gathered}
\Delta^{(0)}=\{0,0.02,0,0.04,0.02,0.01\} \\
\min \left\{\Delta^{(0)}(k)\right\}=\min \{0,0.02,0,0.04,0.02,0.01\}=0 \\
\max \left\{\Delta^{(0)}(k)\right\}=\max \{0,0.02,0,0.04,0.02,0.01\}=0.4
\end{gathered}
$$

Calculate the correlation coefficient

There are only two sequences (reference sequence and comparison sequence), thus we do not calculate the second level of minimum difference and maximum difference.

$$
\eta(k)=\frac{\min \{\Delta(k)\}+P \max \{\Delta(k)\}}{\Delta(k)+P \max \{\Delta(k)\}} \quad,(k=1, \ldots, 6, P=0.5)
$$

Then we have $\eta(k)=\{1,0.5,1,0.33,0.5,0.67\}$

Calculate the relational degree

$$
r_{i}=\frac{1}{n} \sum_{k=1}^{n} \eta_{i}(k)=0.67
$$

$r=0.67$ satisfies the test criterion $r>0.6$ when $P=0.5$

\subsection{Model Test—Posterior Error Test}

Calculate:

$$
\overline{x_{(0)}}=\frac{1}{6}\{77941,48578,224657,556232,1601207,271578\}=870733.2
$$

Calculate the mean square error of ${ }^{x_{(0)}}$ sequence

$$
S_{1}=\left(\frac{\sum\left(x_{(0)}(k)-\overline{x_{(0)}}\right)^{2}}{n-1}\right)^{\frac{1}{2}}=0.3645
$$

Calculate the average residual

$$
\bar{\Delta}=\frac{1}{6}(\Delta(k))=0.017
$$

Calculate the mean square error of residual

$$
S_{2}=\left(\frac{\sum(\Delta(k)-\bar{\Delta})^{2}}{n-1}\right)^{\frac{1}{2}}=0.0146
$$

Calculate the probability of small residual

$$
e_{(k)}=|\Delta(k)-\bar{\Delta}|=\{0.15,0.005,0.015,0.025,0.005,0.005\}
$$

All $e_{i}$ are less than $S_{0}$, thus the probability of small residual $P\left\{e_{i}<S_{0}\right\}=1$, thus model is qualified.

\subsection{Model Solution}

We find that the prediction effect of our model is ideal after testing it, as shown in Table 1. The difference between predicted values and actual values is not significant, so we can predict the number of refugees in recent three years. We via MATLAB figure out the refugee population increased from 5745596 in 2016 and 11379385 in 2017 to 22537333 in 2018, also the increased ratio is larger and larger. Therefore, Europe will encounter more serious tide of refugees and bear a greater burden in next few years.

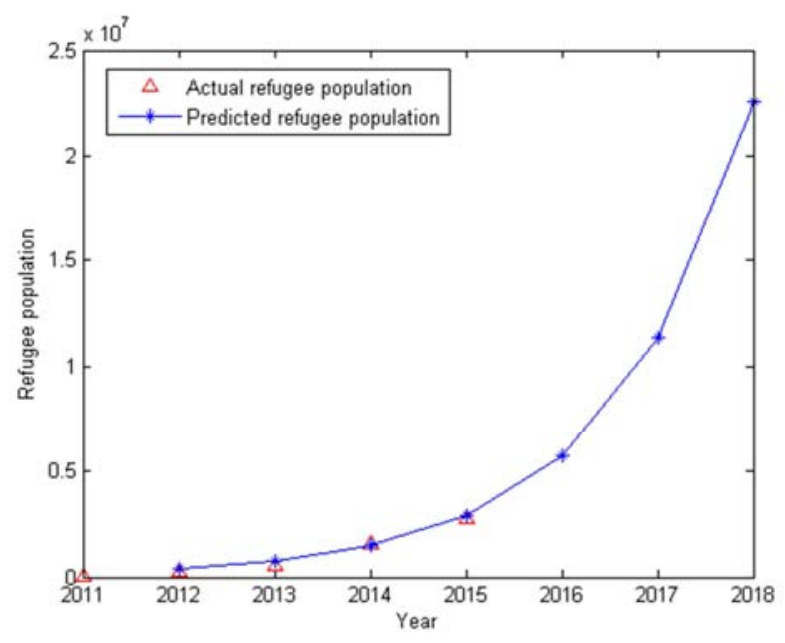

Figure 1. The comparison of refugee population between actual values and predicted values in recent five years.

\section{The Calculation of Refugee Quota}

For the number of each country can house is limited, it needs a reasonable plan for settling refugees to lighten the load on European countries. Therefore, on the basis of multi-objective analysis method [7], we build an optimal model to calculate the certain limited amount of refugees pour into Europe. And then we use the same multi-objective analysis method to distribute the refugees to each recipient country according to the actual situations in different countries.

\subsection{The Building of Quota Model}

For multi-objective analysis, we choose five indicators to analyze the refugee number Europe can accept, such as population density, GDP per capita, capacity per capita, personal welfare amount and the distribution of resources.

The refugees are divided into four types, the elderly, child, young male and young female, then set them in turn as $x_{1} ; x_{2}$; $x_{3}$ and $x_{4}$

For the population density, we choose the population density of the eastern coastal cities in China as the maximum. Because we learn about that the most areas in Europe are habitable except for only a few areas.

$$
\frac{x_{0}+x_{1}+x_{2}+x_{3}+x_{4}}{S} \leq \max R
$$

For the GDP per capita, we choose the $80 \%$ of original level as the minimum. Because we get that there are many developed countries in Europe, it will not seriously Influence their development even if the GDP falls.

$$
\frac{G_{0}}{x_{0}+x_{1}+x_{2}+x_{3}+x_{4}} \geq \min G
$$

Due to the mature welfare policies in Europe countries 
[8], it cannot increase the refugee settlement costs by decreasing the expenditures of welfare. In reference to the large amount of information and documents, we find that it is feasible to reduce the welfare portion to $70 \%$ of original level.

The welfare policies of children and the elderly are the same as the natives in Europe, but the young male is $60 \%$ and the young female is $70 \%$ of the natives in Europe

$$
\frac{F_{0}}{x_{0}+x_{1}+x_{2}+x_{3} \times 60 \%+x_{4} \times 70 \%} \geq \min F
$$

As for refugees, the most important thing is solving the problems of clothing, food and shelter. As mentioned above, it still can meet the daily need of people even if reduce the welfare portion to $70 \%$ of the original level.

$$
\frac{Y_{0}}{x_{0}+x_{1}+x_{2}+x_{3}+x_{4}} \geq \min Y
$$

Some refugees have skills originally, so they can contribute to recipient countries. We define that the elderly and children do not have the ability to work, but there are $70 \%$ in young male and $50 \%$ in young female can work.

$$
x_{3} \times 70 \% \times N+x_{4} \times 60 \% \times N=Z_{n}
$$

Aggregate all the above analyses, and then we have the following equations:

$$
\begin{aligned}
& \max z_{r}=x_{0}+x_{1}+x_{2}+x_{3}+x_{4} \\
& \left\{\begin{array}{l}
\frac{x_{0}+x_{1}+x_{2}+x_{3}+x_{4}}{S} \leq \max R \\
\frac{G_{0}}{x_{0}+x_{1}+x_{2}+x_{3}+x_{4}} \geq \min G \\
\frac{F_{0}}{x_{0}+x_{1}+x_{2}+x_{3} \times 60 \%+x_{4} \times 70 \%} \geq \min F \\
\frac{Y_{0}}{x_{0}+x_{1}+x_{2}+x_{3}+x_{4}} \geq \min Y
\end{array}\right.
\end{aligned}
$$

\begin{tabular}{|c|c|c|c|c|c|}
\hline Factor & Population density & Per capita GDP & Personal welfare amount & Allocation of resources & Per capita capacity \\
\hline European average & 61.1 & 29898 & 19210 & 0.146 & 624565 \\
\hline Constraint limit & 200 & 23918 & 13447 & 0.1022 & 624565 \\
\hline
\end{tabular}

Table 3. Constraint condition chart.

\subsection{Model Solution}

It will obtain the following equation that takes the data of the table into the (27)

$$
\begin{aligned}
& \max z_{r}=x_{0}+x_{1}+x_{2}+x_{3}+x_{4} \\
& \left\{\begin{array}{l}
\frac{7.9 \times 10^{9}+x_{1}+x_{2}+x_{3}+x_{4}}{1.016 \times 10^{7}} \leq 200 \\
\frac{1.45 \times 10^{14}}{7.9 \times 10^{9}+x_{1}+x_{2}+x_{3}+x_{4}} \geq 23918 \\
\frac{5.51 \times 10^{13}+Z_{n}}{7.9 \times 10^{9}+x_{1}+x_{2}+x_{3} \times 60 \%+x_{4} \times 70 \%} \geq 13447 \\
\frac{1.152 \times 10^{9}}{7.9 \times 10^{9}+x_{1}+x_{2}+x_{3}+x_{4}} \geq 0.1022 \\
x_{3} \times 70 \% \times 624565+x_{4} \times 60 \% \times 624565=Z_{n}
\end{array}\right.
\end{aligned}
$$

\begin{tabular}{|c|c|c|c|c|c|}
\hline Factor & Population density & Per capita GDP & Personal welfare amount & Allocation of resources & Per capita capacity \\
\hline German & 261 & 32979 & 12368 & 0.246 & 598565 \\
\hline Hungary & 200 & 9852 & 9853 & 0.293 & 892955 \\
\hline Sweden & 100 & 40231 & 10236 & 0.286 & 562465 \\
\hline Italy & 200 & 23918 & 14256 & 0.321 & 678244 \\
\hline France & 200 & 29144 & 10563 & 0.256 & 568427 \\
\hline
\end{tabular}

Via the lingo we get the $x_{1}=406535 ; x_{2}=469079 ; x_{3}=1282150$ and $x_{4}=1109630$, a total of 3.267 million refugees.

According to the multi-objective analysis of Europe, we use the same limited factors and method to analyze some member states. Here are the constraint conditions on refugee problems to German, Hungary, Sweden, Italy and France.

Table 4. Constraint condition chart.

Put the data of

Table into (28), and then we get the optimal quota plan. It shows that the number of German should be 420210, Hungary should be 304568 , Sweden should be 205863 , Italy should be 275871, and France should be 38134 .

\section{Suggestions}

Peace and development remain as the main theme of the 
present era, however, the European migrant crisis [9] begins to spread at unprecedented speed. The settlement of refugees for humanitarian principle is a very tricky problem need to be solved by European governments. Combining with the realistic factors, we find that there are many other aspects having great impact on refugee quota plan [10], such as national policies, external environmental factors and refugees their own quality. On the basis of above research, we integrate all aspects and make the following recommendations to EU:

(a). Release the detailed refugee quota plan in public and explain how this plan formulates;

(b). Do well in ideological work to general public, let them not to connect terrorists with refugees;

(c). Reinforce the cooperation with international communities and strive for the better solutions;

(d). The once refugees should be got a fair deal like ordinary citizens;

(e). Strengthen basic infrastructure construction and improve the health care system;

(f). Supervise the implementation of refugee quota plan.

Combining with the results of our research, we put forward the above suggestions and sincerely hope these proposals can help refugees go through the tough time as well as EU.

\section{Strengths and Weaknesses}

There are some of the following features in our model.

\subsection{Advantages}

(a). There are many influence factors in the prediction of refugee population, and the structural relationships between them are complex, so it is difficult to do precise calculation. But we use the grey model to integrate all these factors into time and downplay each $\mathrm{f}$ actor's influence on population. It can help us be easier to get the results and achieve more accurate prediction effect.

(b). This model can take consideration of many factors at the same time, so we can use it to give full consideration to their own situations for refugee recipient countries and analyze specific issues for different countries, thus the optimum allocation we get after multi-objective optimization analysis is reasonable. It can separate investigation between different objectives and each of them have successively focus on relationships, so we can get the weight coefficients which used into comprehensive evaluation analysis model.

\subsection{Weaknesses}

(a). For GM $(1,1)$ model [11], there are certain restrictions on its use conditions. It is the model of describing something changes exponentially, so it is always applied in prediction systems which develop and change by exponential law.

(b). The growth of refugee population can be affected greatly by single factor, so it is different from the natural population growth. Therefore, we only can make a short-term prediction in grey model.

(c). It is important to choose constraint conditions and it needs us to further discover constraint conditions hidden in the problem. Meanwhile, it will be better if we transfer the single-objective programming problem into multi-objective decision-making problem. When analyzing and solving the same problem, the model we can build is relatively single and we cannot analyze and compare in different ways on the same model.

\section{Model Extensions}

(a). The grey model can be used in many ways, such as pest control, population growth and the prediction of business outlook. And it is convenient for users to decide whether choose this model only through the accuracy test.

(b). The multi-objective optimization analysis is the reasonable analysis of multi-angle. So it can help us give more comprehensive proposals and consider all kinds of complicated conditions in actual situations. This method also can be used in many ways which determined and limited by multi factors such as the allocation of water resources. In a word, this model has strong scientific nature and practicability.

\section{Conclusions}

Overall, this study first clearly predicts the growth tendency of refugee populations via Grey Model and then gives the optimal refugee quota via Muti-objective Analysis. According to the prediction, the number of refugees will increase from 5.74 million to 11.37 million from 2016 to 2018 , and reach the peak value in 2018 about 22.53 million. Hence, Europe will face tremendous pressure on refugee problems in the next few years. It is not only a management problem, but also a humanitarian trial. The relations between Europe governments, the local people in Europe and refugees are complex. Once the interests of any party are violated, it will become the focus of the world. So it is high time to give an optimal refugee quota plan to distribute the refugees to each member states for normal development in Europe. As OECD Secretary General Angel Gurria said: "Immigration is far from a burden, but a real treasure. [12]" We think the reasonable distribution of refugees would benefit the member states rather than bringing crises. In this paper, we reasonably calculate the specific quota plan about five representative countries. According to our research, we put forward some feasible suggestions to EU. We sincerely hope this research can help EU and member states solve refugee crises promptly and reasonably.

\section{References}

[1] Wang Lei. The Analysis of European Union's Refugee Policy (1980-2014) [D]. East China Normal University master's dissertation.2015.4.

[2] Number displaced worldwide hits record high - UN report http://www. bbc. com/. 
[3] Migrant crisis: http://www.the refugee project.org/.

[4] Roger Zetter, More Labels, Fewer Refugees: Remaking the Refugee Label in an Era of Globalization, Journal of Refugee Studies, 2007, 20(2):172-192.

[5] http://www.nytimes.com/2015/08/28/world/migrants-refugees -europe-syria.html? $\mathrm{r}=0$.

[6] Ming-fang He. The Population Prediction based on Gray System [D]. South China University of Technology.2012.05.

[7] Mao-guo Gong, Li-cheng Jiao, Dong-dong Yang, Wen-ping Wang. Research on Evolutionary Multi-Objective Optimization Algorithms [J]. Journal of Software, Vol.20 No.2 February 2009.
[8] James Hollield Philip MartinPia Orrenius, Controlling Immigration: A Global Per-spective (Third Edition), 2014.

[9] UNHCR, As Syria Crisis continues, UNHCR urges EU States to Uphold Common Asylum System Principles, October, 2012.

[10] Eleonore Kofman, Gender and International Migration in Europe: Employment, Welfare, and Politics, 2000.

[11] Jun Zhang. Improvement of Gray Forecasting Model And its Application [D]. Xi'an University of Technology.2008.03.

[12] Fang Hua. Refugee Protection and Europe's Dilemma in the Management of Refugee Wave from the Middle East [J]. West Asia and Africa.2015.06. 